\title{
ENERGY CONSUMPTION AND UTILITY PRACTICES IN INDIA: AN EMPIRICAL ANALYSIS
}

\author{
Dr. K. Ganesamurthy ${ }^{1 凶}$, Dr. A. Morarji ${ }^{2} \underset{ }{ }$, Mrs. N. Shanmuga Priya ${ }^{3 凶}$ \\ ${ }^{1}$ Project Director-ICSSR \& Assistant Professor, Department of Corporate Secretaryship Alagappa \\ University Karaikudi, Tamilnadu, India \\ 2 Project Co-Director-ICSSR \& Professor, Department of Corporate Secretaryship Alagappa \\ University Karaikudi, Tamilnadu, India \\ ${ }^{3}$ Project Assistant -ICSSR, Department of Corporate Secretaryship Alagappa University Karaikudi, \\ Tamilnadu, India
}

DOI: https://doi.org/10.29121/ijetmr.v7.i7.2020.723

Article Citation: Dr. K.

Ganesamurthy, Dr. A. Morarji, and

Mrs. N. Shanmuga Priya. (2020).

ENERGY CONSUMPTION AND

UTILITY PRACTICES IN INDIA: AN EMPIRICAL ANALYSIS. International Journal of Engineering Technologies and Management Research, 7(7), 42-49.

https://doi.org/10.29121/ijetmr.v7 .i7.2020.723

Published Date: 18 July 2020

Keywords:

Electrical Energy

Agriculture

Energy Consumption

Energy Utility

Renewable

\section{ABSTRACT}

In India, the sources of energy availability to the human development has been advocated since independence, so much so that the adequate quantity and quality of electricity, and measured by per capita consumption, is associated in most economies as a key Human Development Index. It is expected that the nation, which is already in the forefront of urbanization and industrialization in the country, proposes to be a global hub of manufacturing. Such a vision, if continued by successive governments, will leads to a scenario where the demand for electricity is most likely to increase year after year for decades. This Paper attempts to identify the sources of electrical energy in India. The growth of agriculture, manufacturing and service sectors has been possible to modify the energy in every year and also utilization of new technologies in their production. As a result, the electrical energy is leads to greater importance for agriculture and farmers have better control over the availability of energy for productive oriented. Based on the utilization of the energy the audit reports of various departments such as agriculture, corporate and Government etc., and electric utilities are some time at variance in all field. This paper highlights the need for the electricity and strategy for optimum utilization of resource like electrical energy and renewable energy in India and it's bringing into the plan of action to the corporate and government in India for sustainability.

\section{INTRODUCTION}

Electricity is being considered as a key deciding factor for a nation's progress, thus differentiating nation as developing or developed. The linkage between Tamil Nadu, as well as India, possessing a vast population spread across vastly diverse geographical, climatic and cultural mixture, depends on electricity for adequate progress in Human Development Index. To plan and implement the electricity infrastructure of the state so as to satisfactorily meet the requirements of electricity sector in future (say by 2050), which are likely to be much more demanding than the present scenario, could be a considerable challenge even in the normal circumstances. But to ensure such a

(C) 2020 The Author(s). This is an open access article distributed under the terms of the Creative Commons Attribution License, which permits unrestricted use, distribution, and reproduction in any medium, provided the original author and source are credited. 
Energy Consumption and Utility Practices in India: An Empirical Analysis

transformation by 2050 in a people centric and environmentally friendly way will be a huge and onerous task requiring effective participation by various stake holders.

\section{STATEMENT OF THE PROBLEM}

Energy is an integral part of today's modern life. It has become the blood of our day to day life. But it is not free. It comes at a monetary price but more than that it comes at environment cost too. Every farming activity and agricultural allied undertakings need a specific amount of energy to undertake the process and operations. It could be in the form of electrical energy, thermal energy or any other forms of energy use. During good old days, when energy was in surplus, no one cared about designing the system to minimize the energy use. In addition to this, designers used to take huge safety margins on one side and extra precaution on initial capital investment on the other, which also led to extra amount of energy consumption to undertake a specific task. However, the situation has changed now dramatically and survival becomes a question mark in front of most of the farmers that those days enjoying a very comfortable position earlier. Under such a scenario, effective energy management strategy is the only option for survival. To cut price, the cost of production needs to be reduced. The energy cost is 5 to $25 \%$ or even more in Indian agriculture. Hence the present study is to attempt sustainability of development of Human Development Index through availability of energy, utilization and growth of agriculture.

\section{REVIEW OF LITERATURE}

The following literatures are related to energy conservation and utilization of various sectors;

Laxmi Rajkumari (2020), in this article revealed, Karnataka is a highly progressive and rapidly growing state in India, with huge potential for industrial growth; however, it grapples with power deficits and other problems in electricity sector, which make it a good case study for Indian electricity sector. Given the importance of electricity in the urbanization and growth process, the paper analyses the electricity consumption trend in Karnataka, examine its causality with economic growth at aggregate and sectoral levels using Granger causality test, and forecast the future electricity consumption applying Holt-Winters smoothening (no seasonality) technique. The Granger causality tests reveal that there is no causality relation (neutrality hypothesis) between electricity consumption and economic growth in Karnataka, for total, agricultural and industrial consumption.

Jat et al. (2020): In the study, Indo-Genetic plains of South Asia, the triple challenges of diminishing farm profitability, deteriorating natural resources and energy deficits threaten conventional agricultural sustainability. It was concluded that crop residues biomass contributed maximum $(79 \%)$ in total input energy $\left(1,68,556 \mathrm{MJ}^{-1}\right)$ in conservation agriculture (CA) based systems, however fertilizer application (non-renewable energy source) contributed maximum (50\%) to the total energy (40,636 $\mathrm{MJ} \mathrm{ha}^{-1}$ ) in conventional tillage (CT) based maize-wheat cropping system.CA based maize systems recorded higher input energy and energy intensiveness by 23 and $57 \%$ respectively, and recorded almost $44 \%$ lower energy use efficiency and energy productivity compared to CT based maize systems.

Mustafa Ali et al. (2019), made a study on Sustainable food production is a key concern across countries in South Asia. This paper analyzed the environmental impact of energy utilization in agriculture in India and Pakistan. More specifically, the study analyzes the trends of fuel and electricity consumption for crop production in these countries during a ten-year period between the years 2002 and 2011.0verall, this study showed that further electrification of agriculture will not necessarily lead to cleaner environment in these countries. Due to high population growth rates, energy consumption for agriculture is expected to grow in these countries in the future.

Arvind Singh and N.S.Thakkur (2019), in this study revealed, India is agriculture based economy, and also has a forest cover that comprises roughly $24 \%$ of its total geographic area. Thus, an abundance of biomass, in the form of waste material is readily available throughout the country annually. In this paper, the most recent statistical data regarding energy generation through bioenergy resources has been presented using currently available sources. Brief descriptions of gasification conversion routes have also been included, with their sustainability conditions, as well as the government policies necessary for implementation in the Indian context. and BiswajitGhosh and NamitaChakma (2019), in this study carried, Agro-ecosystem is an open system that represents a complex interaction with the environment in term of energy transformation. 
Jeslin Drusila Nesamalar et al. (2017),"This article provides a comprehensive review on Tamilnadu's achievement in extracting renewable energyTo ensure continuous growth in renewable sector, more public awareness and Research and Development sector should be encouraged in Tamilnadu" and W.Julice Sudhir \& Dr.A.Morarji (2016), in this study revealed that the energy management can make the employees to practice conservation and effective utilization of energy. The employees' views disclose that the continuous training programs given by the energy managers will develop energy saving attitude. The respondent energy managers also accepted the fact that the energy management practices are as per the legal provisions, but they are not transparent. The need for energy management is evident from the acceptance index framed by the research. The Energy Conservation Model (ECM) developed by the researcher will also help the company to ensure the effective energy management. The energy management practices and the positive attitudes of the employees will result in energy conservation and sustainability.

Shiv Kumar Lohan and Sushil Sharma (2012), Jammu and Kashmir State of India is one of the energy starved states despite of having tremendous potential for utilization of renewable energy. The natural energy sources like sunshine, wind, vegetation, water flow, biomass and other biological wastes are abundantly available in the state yet are not being potentially harnessed resulting in very low per capita energy availability forcing peoples to use wood resulting into deforestation. The fossils fuels, which pollute the environment, are extensively utilized even though they are not sustainable. This paper presents an overview of the present status of renewable energy development and summarizes key issues in each of the major industrial segments. It also examines crucial gaps in the renewable energy market, describes the goals set out by various government programs, and estimates the resources and effort required to meet these goals.

Narayanamoorthy (2006), has concluded that that the linkages between the adoption of DMI and electivity use on three water intensive crops namely banana, grapes and sugarcane, using farm level survey data collected from 200 farmers selected from Maharashtra, a western state of India.

\section{OBJECTIVES OF THE STUDY}

1) To study the sources of energy production and Demand in India.

2) To critically examine the generation and growth in conventional energy in India.

3) To develop a coordination between utilities generation and demand for optimization of utilities.

\section{METHODOLOGY OF THE STUDY}

Data comprising sample survey and secondary sources were collected and presented in this research paper. Descriptive research is considered most appropriate method for the present study. This study was carried out on a sample survey method. Hence, it is descriptive and analytical.

\section{DATA COLLECTION}

The sources of data consist of primary and secondary data obtained from the records and reports maintained and published by the Department of agriculture in India and Bureau of Energy Efficiency of India, doctoral thesis of various institutions, books, journals of repute, various other published and unpublished reports and so on.

\section{FRAME WORK OF ANALYSIS}

To analyse the data collected through secondary sources and applied as percentage analyse, demand and supply forecast analysis used. 


\section{DATA ANALYSIS AND INTERPRETATION}

Table 1: Production of Electrical Energy in India

\begin{tabular}{|c|c|c|}
\hline Sector & MW & \% of Total \\
\hline Central Sector & 93,477 & $25.2 \%$ \\
\hline State Sector & 103,322 & $27.9 \%$ \\
\hline Private Sector & 173,549 & $46.9 \%$ \\
\hline Total & $3,70,348$ & \\
\hline
\end{tabular}

*Source: Installed capacity in respect of RES (MNRE) as on 30.04.2020.

From the above table 1, it is evident that there is electrical energy produced in India. In particularly Central Sector are 25.2\%, State Sector are 27.9\%, Private Sector are 46.9\% of Mega Watt electrical energy produced. The highest MW of Energy Produced among the Private Sector. It is reflects the growth of Private Sectors in India.

Table 2: Sources of Energy in India

\begin{tabular}{|c|c|c|}
\hline Fuel & MW & $\%$ of Total \\
\hline Total Thermal & $2,30,600$ & $62.8 \%$ \\
\hline Coal & $1,98,525$ & $54.2 \%$ \\
\hline Lignite & 6,610 & $1.7 \%$ \\
\hline Gas & 24,955 & $6.7 \%$ \\
\hline Diesel & 510 & $0.1 \%$ \\
\hline Hydro (Renewable) & 45,699 & $12.4 \%$ \\
\hline Nuclear & 6,780 & $1.9 \%$ \\
\hline Renewable Energy Sources* (MNRE) & 87,269 & $23.6 \%$ \\
\hline Total & 370,348 & \\
\hline
\end{tabular}

* Source: Installed capacity in respect of RES (MNRE) as on 30.04.2020

It is evident from table. 2 that the percentage of energy sources from the sector wise are the highest percentage is $62.8 \%$ of energy in Thermal, RES (MNRE) is $23.6 \%$, Hydro (Renewable) energy is $12.4 \%$, and Nuclear energy is $1.9 \%$ in India.

Table 3: Electricity Generation and Growth in Conventional Generation in The Country During 2009-10 To

\begin{tabular}{|c|c|c|}
\hline Year & Energy Generation from Conventional Source (BU) & \% of growth \\
\hline $2009-10$ & 771.551 & 6.6 \\
\hline $2010-11$ & 811.143 & 5.56 \\
\hline $2011-12$ & 876.887 & 8.11 \\
\hline $2012-13$ & 912.056 & 4.01 \\
\hline $2013-14$ & 967.150 & 6.04 \\
\hline $2014-15$ & 1048.673 & 8.43 \\
\hline $2015-16$ & 1107.822 & 5.64 \\
\hline $2016-17$ & 1160.141 & 4.72 \\
\hline $2017-18$ & 1206.306 & 3.98 \\
\hline
\end{tabular}


Dr. K. Ganesamurthy, Dr. A. Morarji, and Mrs. N. Shanmuga Priya

\begin{tabular}{|c|c|c|}
\hline Year & Energy Generation from Conventional Source (BU) & \% of growth \\
\hline $2018-19$ & 1249.337 & 3.57 \\
\hline $2019-20$ & 1252.611 & 0.26 \\
\hline $2020-21$ & 91.913 & -22.85 \\
\hline
\end{tabular}

* Source: Upto April 2020 (Provisional), Source: CEA

The above table.3, the electricity generation target of conventional sources for the year 2020-21 has been fixed as 1330 Billion Unit (BU). i.e. growth of around 6.33\% over actual conventional generation of $1250.784 \mathrm{BU}$ for the previous year (2019-20). The conventional generation during 2019-20 was 1250.784 BU as compared to 1249.337 BU generated during 2018-19, representing a growth of about $0.12 \%$.

The electricity generation target of conventional sources for the year 2020-21 was fixed at $1330 \mathrm{BU}$ comprising of 1138.533 BU thermal; 140.357 BU hydro; 43.880 nuclear; and 7.230 BU import from Bhutan.

Table 4: The Plf In the Country (Coal \& Lignite Based) From 2009-10 T0 2020-21

\begin{tabular}{|c|c|c|c|c|}
\hline \multirow{2}{*}{ Year } & PLF & \multicolumn{3}{|c|}{ Sector-wise PLF (\%) } \\
\cline { 2 - 5 } & $\%$ & Central & State & Private \\
\hline $2009-10$ & 77.5 & 85.5 & 70.9 & 83.9 \\
\hline $2010-11$ & 75.1 & 85.1 & 66.7 & 80.7 \\
\hline $2011-12$ & 73.3 & 82.1 & 68.0 & 69.5 \\
\hline $2012-13$ & 69.9 & 79.2 & 65.6 & 64.1 \\
\hline $2013-14$ & 65.60 & 76.10 & 59.10 & 62.10 \\
\hline $2014-15$ & 64.46 & 73.96 & 59.83 & 60.58 \\
\hline $2015-16$ & 62.29 & 72.52 & 55.41 & 60.49 \\
\hline $2016-17$ & 59.88 & 71.98 & 54.35 & 55.73 \\
\hline $2017-18$ & 60.67 & 72.35 & 56.83 & 55.32 \\
\hline $2018-19$ & 61.07 & 72.64 & 57.81 & 55.24 \\
\hline $2019-20$ & 56.08 & 65.36 & 50.26 & 54.73 \\
\hline $2020-21$ & 42.40 & 49.86 & 33.48 & 44.28 \\
\hline
\end{tabular}

** Source: Upto April 2020 (Provisional), Source: CEA

The above table.4 exhibits, the highest plant load factor is $2009-10$, on $2010-11$ onwards the coal. Lignites are gradually decreased. In 2020-21 expected the PLF is 44.28 percentages.

Table 5: The Power Supply Position in The Country During 2009-10 to 2020-21

\begin{tabular}{|c|c|c|c|c|c|c|c|c|}
\hline \multirow{2}{*}{ Year } & \multicolumn{4}{|c|}{ Energy } & \multicolumn{3}{c|}{ Peak } \\
& Requirement & Availability & \multicolumn{2}{c|}{$\begin{array}{c}\text { Surplus (+)/ } \\
\text { Deficts (-) }\end{array}$} & Peak Demand & Peak Met & \multicolumn{2}{c|}{$\begin{array}{c}\text { Surplus (+) / } \\
\text { Deficts (-) }\end{array}$} \\
\cline { 2 - 9 } & $(\mathrm{MU})$ & $(\mathrm{MU})$ & $(\mathrm{MU})$ & $(\%)$ & $(\mathrm{MW})$ & $(\mathrm{MW})$ & $(\mathrm{MW})$ & $(\%)$ \\
\hline $2009-10$ & $8,30,594$ & $7,46,644$ & $-83,950$ & -10.1 & $1,19,166$ & $1,04,009$ & $-15,157$ & -12.7 \\
\hline
\end{tabular}


Energy Consumption and Utility Practices in India: An Empirical Analysis

\begin{tabular}{|c|c|c|c|c|c|c|c|c|}
\hline & \multicolumn{5}{|c}{ Energy } & \multicolumn{5}{c|}{ Peak } \\
\hline $2010-11$ & $8,61,591$ & $7,88,355$ & $-73,236$ & -8.5 & $1,22,287$ & $1,10,256$ & $-12,031$ & -9.8 \\
\hline $2011-12$ & $9,37,199$ & $8,57,886$ & $-79,313$ & -8.5 & $1,30,006$ & $1,16,191$ & $-13,815$ & -10.6 \\
\hline $2012-13$ & $9,95,557$ & $9,08,652$ & $-86,905$ & -8.7 & $1,35,453$ & $1,23,294$ & $-12,159$ & -9.0 \\
\hline $2013-14$ & $10,02,257$ & $9,59,829$ & $-42,428$ & -4.2 & $1,35,918$ & $1,29,815$ & $-6,103$ & -4.5 \\
\hline $2014-15$ & $10,68,923$ & $10,30,785$ & $-38,138$ & -3.6 & $1,48,166$ & $1,41,160$ & $-7,006$ & -4.7 \\
\hline $2015-16$ & $11,14,408$ & $10,90,850$ & $-23,558$ & -2.1 & $1,53,366$ & $1,48,463$ & $-4,903$ & -3.2 \\
\hline $2016-17$ & $11,42,929$ & $11,35,334$ & $-7,595$ & -0.7 & $1,59,542$ & $1,56,934$ & $-2,608$ & -1.6 \\
\hline $2017-18$ & $12,13,326$ & $12,04,697$ & $-8,629$ & -0.7 & $1,64,066$ & $1,60,752$ & $-3,314$ & -2.0 \\
\hline $2018-19$ & $12,74,595$ & $12,67,526$ & $-7,070$ & -0.6 & $1,77,022$ & $1,75,528$ & $-1,494$ & -0.8 \\
\hline $2019-20$ & $12,90,247$ & $12,83,690$ & $-6,557$ & -0.5 & $1,83,804$ & $1,82,533$ & $-1,271$ & -0.7 \\
\hline $2020-21 *$ & 85,608 & 85,164 & -445 & -0.5 & $1,33,315$ & $1,32,779$ & -536 & -0.4 \\
\hline
\end{tabular}

*Source: Up to April 2020 (Provisional), Source: CEA

The above table.5 revealed that, the power supply was decreased in 2009-10 while the requirement of energy was 8,30,594 MU, but the availability energy only 7,46,644 MU. So, the deficit was $\quad-12.7 \%$. In $2019-20$ the requirement of energy was $12,90,247 \mathrm{MU}$, the availability of power supply was $12,83,690$. It was small changes in compared to 2009-10.

\section{CONCLUSION}

The Present study concludes that the energy consumption and utility practices in India. It was fluctuating in every year. The conventional sources of energy are very merger and decreased. The renewable sources are also scarcity from 2009-10 to 2020-21. Therefore, the consumers and various sectors must utilize the properly and must concentrate the energy leakages and wastages. Energy wastage is economic lose to the country and affect the growth of the sectors. It is fundamental duty energy citizen to presence the precise energy for the future India.

Dr. K. Ganesamurthy (first author) and Dr. A. Morarji (Co-author) great fully acknowledges ICSSR minor project scheme. The research works carryout and its publication in the Journal.

\section{SOURCES OF FUNDING}

None.

\section{CONFLICT OF INTEREST}

None.

\section{ACKNOWLEDGMENT}

None. 


\section{REFERENCES}

[1] Arvind Singh, N.S.Thakkur (2019), Small scale biomass gasification plants for electricity generation in India: Resources, installation, technical aspects, sustainability criteria \& policy, Science Direct, Renewable Energy Focus, Volume 28, March 2019, Pages 112-126.

[2] E.A. Abdelaziz, R.Saidur (2011), Energy saving strategies in industrial sector , Vol.15, Issue1, January 2011, Pg. No.150-168.

[3] H.S.Jat, R.D.Jat, R.K.Nanwal, Shiv Kumar Lohan (2020), Energy use efficiency of crop residue management for sustainable energy and agriculture conservation in NW India, Science Direct -Renewable Energy, Volume 155, 15 April 2020, Pages 1372-1382.

[4] Laxmi Rajkumari (2020), Relation between electricity consumption and economic growth in Karnataka, India: An aggregate and sector-wise analysis The Electricity Journal - Science Direct Volume 33, Issue 5, 11 April 2020, Pages.106768.

[5] Matt Croucher, "Potential Problems and Limitations of Energy Conservation and Energy Efficiency", Energy Policy, 2011, Vol. 39(10), pp. 5795-5799.

[6] Muhammad Shahbaz, Thi Hong VanHoang and David Roubaud (2017), Energy consumption, financial development and economic growth in India: New evidence from a nonlinear and asymmetric analysis, Energy Economics Volume 63, March 2017, Pages 199-212.

[7] Mustafa Ali and Yong Geng, Dawn Robins 2019, "Impact assessment of energy utilization in agriculture for India and Pakistan" Science of the Total Environment, Vol.648, 15 January 2019, Pg 1520-1526.

[8] Narayanamoorthy A., Case Study of a Successful Paddy Cultivator in Pudukkottati District in Tamil Nadu, Indian Jour.al of Agricultural Economics, July-September 1990, pp.374-378

[9] Ozkan B.H., Akcaoz and Fert C., Energy Input-Output Analysis in Furkish Agriculture, Renewable Energy, Vol. No.29, 2004, pp.39-51.

[10] Ramachandra Murthy K.V.S., and Ramalinga Raju M., Analysis Electrical Energy Consumption of Agricultural Sector in Indian Contest, ARPN Journal of Engineering and Applied Sciences, 4(2): 2009.

[11] Shiv Kumar Lohan and Sushil Sharma 2012, "Present status of renewable energy resources in Jammu and Kashmir State of India”, Renewable an Sustainable Energy Reviews, Vol.16, Issue5, June 2012, Pg.3251-3258

[12] Subhash Mallah, Bansai N.K., "Energy Efficiency Potential Assessments for Economic Sectors in India", International Journal of Global Energy Issues, 2009, Vol. 32, No.1-2.

[13] W. Julice Sudhir and Dr.A.Morarji (2016), "Energy Management Practices Of Paper Industry In Tamil Nadu", Ph.D. thesis. 